\title{
Thermal performance of ultra-thin flattened heat pipes
}

\author{
Wenjie Zhou a, Peida Xie a, Yong Li ${ }^{\text {a,*, }}$ Yuying Yan ${ }^{\text {b,* }, ~ B o ~ L i ~}{ }^{b}$ \\ ${ }^{a}$ School of Mechanical and Automotive Engineering, South China University of Technology, \\ Guangzhou 510640, China. \\ ${ }^{\mathrm{b}}$ Fluids \& Thermal Engineering Research Group, Faculty of Engineering, University of Nottingham, \\ UK. \\ *Corresponding authors: meliyong@scut.edu.cn; yuying.yan@nottingham.ac.uk
}


Abstract: This study investigates the thermal performance of composite ultra-thin heat pipes (UTHPs). UTHPs are fabricated by flattening cylindrical heat pipes with outer diameter of $2 \mathrm{~mm}$. The thickness and width were $0.8 \mathrm{~mm}$ and $2.7 \mathrm{~mm}$, respectively. The composite wick structure is made of sintered copper foam-mesh wick (CFMW). CFMW combines the good heat transfer performance of copper foam and the high mechanical strength of mesh. The manufacturing process of UTHP was studied and the thermal performance of UTHP samples were investigated experimentally. The results indicate that the optimum filling ratio of UTHPs is $100 \%$ and the maximum temperature difference is $3.7^{\circ} \mathrm{C}$ under the maximum heat transport capacity of $5 \mathrm{~W}$. The thermal resistances of UTHPs increase gradually with the heat power before drying out. Too low or too high filling ratios will reduce the heat transfer efficiency of UTHPs by increasing the thermal resistances. With the optimum filling ratio of $100 \%$, the evaporation thermal resistance of UTHP is found to be $0.29 \mathrm{~K} / \mathrm{W}$ and the condensation thermal resistance is $0.45 \mathrm{~K} / \mathrm{W}$ at the heat load of $5 \mathrm{~W}$.

Keywords: ultra-thin heat pipe, composite wick, filling ratio, thermal performance 


\begin{tabular}{|llll|}
\hline \multicolumn{2}{|l|}{ Nomenclature } & & \\
$L$ & length, $\mathrm{mm}$ & $\rho$ & density, $\mathrm{g} / \mathrm{mm}^{3}$ \\
$d$ & diameter, $\mathrm{mm}$ & Subscripts & \\
$I$ & current, $\mathrm{A}$ & $a$ & adiabatic \\
$M$ & mass, $\mathrm{g}$ & $a v e$ & average \\
$Q$ & heat input, $\mathrm{W}$ & $c$ & condenser \\
$R$ & thermal resistance, $\mathrm{K} / \mathrm{W}$ & $c p$ & copper foam \\
$T$ & temperature, ${ }^{\circ} \mathrm{C}$ & $e$ & evaporator \\
$t h$ & thickness, $\mathrm{mm}$ & $h$ & hole \\
$U$ & voltage, $\mathrm{V}$ & $m$ & mesh \\
$W$ & width, $\mathrm{mm}$ & $o$ & outer \\
$V$ & volume, $\mathrm{mm}{ }^{3}$ & $p$ & pore \\
& & $w$ & wick \\
Greek symbols & $v$ & vapor \\
$\varepsilon$ & porosity, $\%$ & & \\
$\eta$ & filling ratio, $\%$ & & \\
\hline
\end{tabular}

\section{Introduction}

With the performance enhancement and size reduction of smart phones [1], the power density has become higher and higher, resulting in more and more serious heat dissipation problem. Heat pipes, considered as super thermal conductors, have been widely used in the electronic devices because of their small sizes, light weight structures and excellent heat transfer performance [2-4].

Because the spaces of the electronic devices for heat dissipation are limited, heat pipes are usually flattened before applied [5]. Flattened heat pipes have been designed for high heat flux occasions and widely used in the narrow space of thermal control components [6-8]. The flattened structure of ultra-thin heat pipes (UTHPs) is usually made by flattening cylindrical heat pipes. The flattening process is very efficient and mass production is easy to realize without complex equipment. Therefore, UTHPs flattened by cylindrical heat pipes are studied in this work.

As for the cylindrical heat pipes, many heat transfer limits should be considered to research the 
heat transfer performance of UTHPs. UTHPs with different wick structures have different thermal characteristics. Do et al. [9] theoretically analyzed the performance of grooved heat pipes with the vapor-liquid inter-facial shear theory and insisted that the dragging limit was the main heat transfer limit. Liou et al. [10] investigated the thermal performance of flat plate heat pipes with mesh wick. The experiment showed that no nucleate boiling occurred in the evaporator section but quiescent surface, even though at the maximum super-heat of $8 \mathrm{~K}$. The results indicated that water with larger latent heat and larger surface tension was less likely to cause nucleate boiling in flat plate heat pipes. Wong et al. [11] investigated the evaporator resistance of flat plate heat pipes with sintered copper-powder wick structure. The results showed that a thin water film was sustained by the wick with fine pores at the bottom under large heat input power. The minimum evaporation resistance was yielded by a composite wick with only coarse spherical powder in the evaporator.

Filling ratio determines the mass of working fluid that could transfer the heat of a heat pipe. If a heat pipe with a low filling ratio works under a high heating power, local overheating may occur. And if it works in a low heating power with a high filling ratio, liquid clogging may appear. Both local overheating and liquid clogging can seriously degrade the heat transfer performance of heat pipes, so it's very important to choose the optimum filling ratio. Lips et al. [12] studied the effects of filling ratio and vapor thickness on the thermal performance of flat plate heat pipes and found that the vapor space thickness and filling ratio strongly influenced the level of the meniscus curvature radii and therefore modified the maximum capillary pressure. Chen et al. [13] experimentally investigated the filling ratio effect on the thermal performance of flat plate heat pipe made of Al 6061. The results showed that the optimum filling ratio of flat plate heat pipes with groove wick was $25 \%$, and the maximum heat transport capability was $47 \mathrm{~W}$. 
In the researches, the UTHPs usually fabricated by flattening cylindrical heat pipes with outer diameter of $6 \mathrm{~mm}$. Tao et al. [14] investigated the performance of UTHPs flattened to different thicknesses from $6 \mathrm{~mm}$ outer diameter with groove wick structures. Li et al. [15] studied the thermal performance of UTHPs with bilateral sintered powder wick structures and discovered that the flattening thickness exerted a critical influence in the thermal performance. Lin and Wong [16] examined the performance degradation of flattened heat pipes with the sintered-powder wick and groove wick. The ultra-thin heat pipes were flattened from cylindrical heat pipes with $6 \mathrm{~mm}$ outer diameter and with the length of $300 \mathrm{~mm}$.

However, narrow heat dissipation space of smart phones not only limits the thickness of the heat pipes, but also limits their width. The outer diameter of cylindrical heat pipes basically determines the width of UTHPs after flattening. If the cylindrical heat pipes with $6 \mathrm{~mm}$ outer diameter are flattened to $0.8 \mathrm{~mm}$, the width of the UTHPs is about $9.0 \mathrm{~mm}$. But if $2 \mathrm{~mm}$ outer diameter heat pipes are flattened to $0.8 \mathrm{~mm}$, the width of the UTHPs is only about $2.7 \mathrm{~mm}$. The manufacturing process of $2 \mathrm{~mm}$ outer diameter heat pipes is significantly different from the conventional diameter heat pipes, which is more difficult. Therefore, the manufacturing process and thermal performances of composite UTHPs flattened by $2 \mathrm{~mm}$ outer diameter cylindrical heat pipes with thickness of $0.8 \mathrm{~mm}$ are studied.

\section{UTHP specification}

\subsection{Experimental samples}

The composite UTHPs with thickness of $0.8 \mathrm{~mm}$ were fabricated by flattening cylindrical heat pipes with outer diameter of $2 \mathrm{~mm}$. The wick structure of UTHPs is made of copper foam-mesh wick (CFMW). The structure of the heat pipe is illustrated in Fig. 1 and the parameters are given in Table 1. 
The wick structures are shown in Fig. 2.

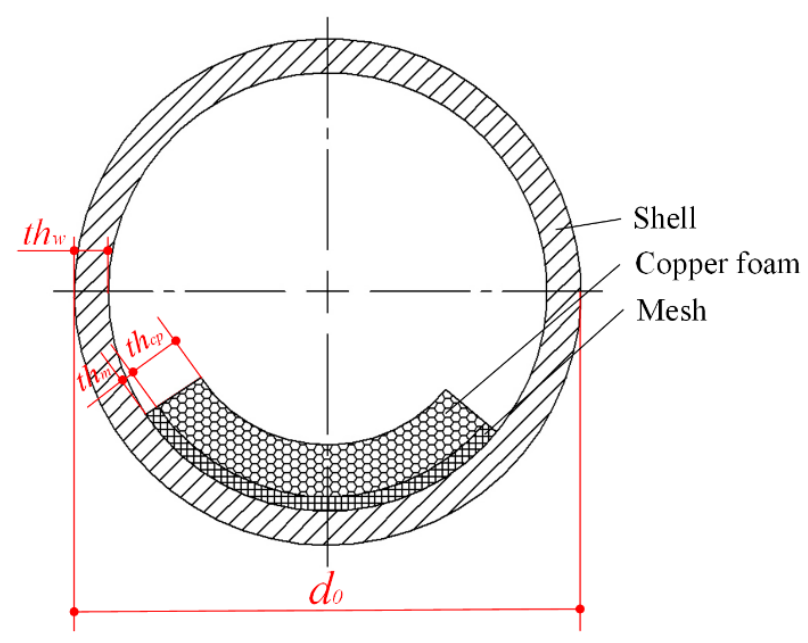

Fig. 1. Schematic of the cylindrical heat pipe.

Table 1 Parameters of cylindrical heat pipe

\begin{tabular}{lc}
\hline Parameters & Dimension / material \\
\hline Tube material & Copper $(\mathrm{C} 1020)$ \\
$d_{o}(\mathrm{~mm})$ & 2 \\
$t h_{w}(\mathrm{~mm})$ & 0.2 \\
$t h_{c p}(\mathrm{~mm})$ & 0.3 \\
$p_{c p}$ & $80 \%$ \\
$t h_{m}(\mathrm{~mm})$ & 0.1 \\
$d_{h m}(\mathrm{~mm})$ & 0.074 \\
$p_{m}$ & $80 \%$ \\
\hline
\end{tabular}

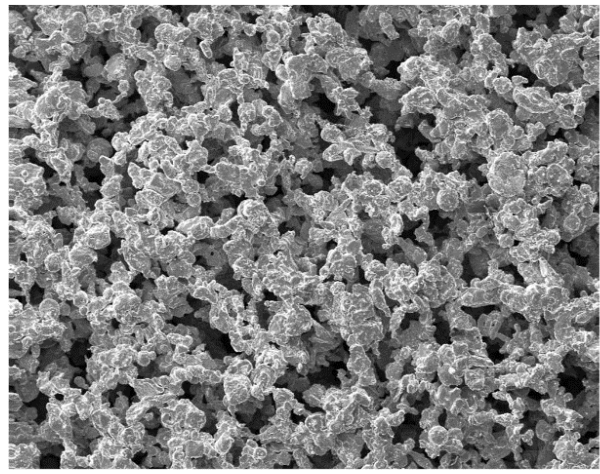

(a)

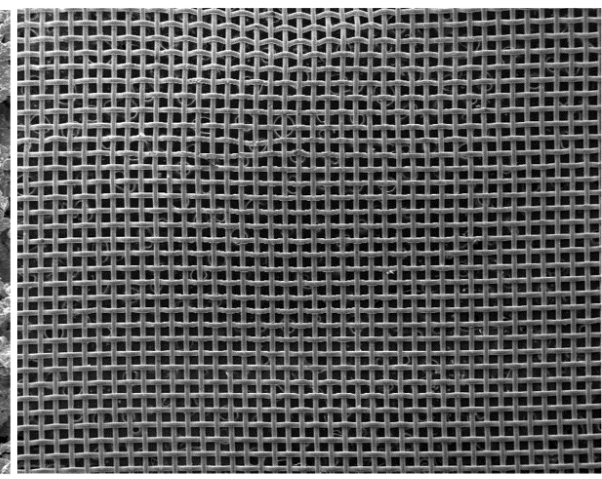

(b)

Fig. 2. SEM photograph of wick structures: (a) copper foam and (b) mesh. 


\subsection{Fabrication of UTHP samples}

The common forms of the wick structures are grooved, sintered powder, copper foam and mesh [17]. Groove wick and sintered powder wick are applied into mass production because these wicks are easier to manufacture than other wicks. Due to poor anti-gravity performance, grooved structured ultra-thinned heat pipes have been rarely used in industries [18]. And the cylindrical heat pipe with outer dimeter of $2 \mathrm{~mm}$ is too small to adopt the sintered powder wicks, because the powder is very difficult to fill into the tube. So the wick structures like copper foam and mesh are taken into consideration. The CFMW combines the good heat transfer performance of the copper foam and the high mechanical strength of the mesh. The most important processes for making UTHP samples are the CFMW fabrication process and the UTHP wick sintering process, which are shown in Fig. 3 and Fig. 4, respectively.

Firstly, copper foam with the thickness of $0.3 \mathrm{~mm}$ and mesh with the thickness of $0.1 \mathrm{~mm}$ are cut into pieces. Then a copper foam piece and a mesh piece are put together and clamped by two graphite moulds. Secondly, the combined piece is sintered for 3 hours at the temperature of $950{ }^{\circ} \mathrm{C}$ under reducing atmosphere. After sintering, CFMW is taken out and cut into slices with the length of $100 \mathrm{~mm}$ and the width of $1.3 \mathrm{~mm}$. Then a stainless mandrel (the material is $310 \mathrm{~S}$ ) is used to insert the CFMW slice into the copper tuber, which ensures close contact between the CFMW and the inner wall of tuber. Thirdly, the tube is sintered for 3 hours at the temperature of $950{ }^{\circ} \mathrm{C}$ under reducing atmosphere. The stainless mandrel is removed after the sintering process. To manufacture UTHPs successively, there are many other following processes, such as liquid charging process, first vacuuming process, second vacuuming process, welding process, and flattening process. Fig. 5 shows the cylindrical heat pipe samples and the UTHP samples. 


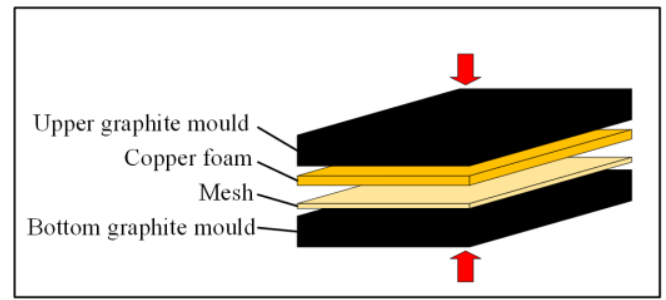

Clamping Process

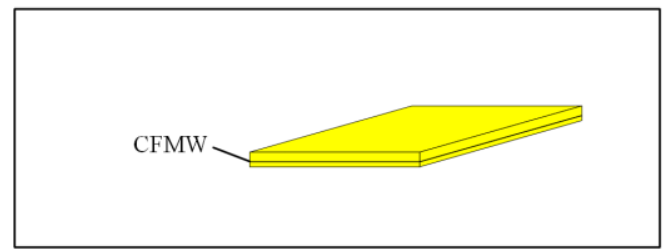

Levelling Process

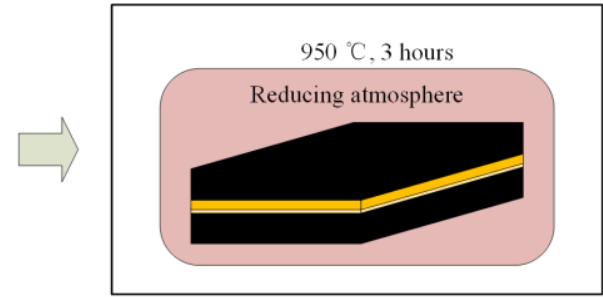

Sintering Process

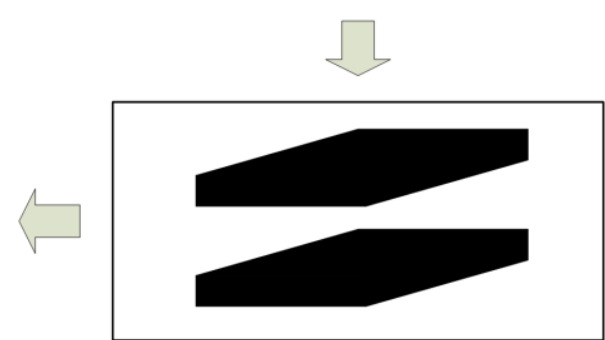

Opening Process

Fig. 3. Fabrication process of CFMW

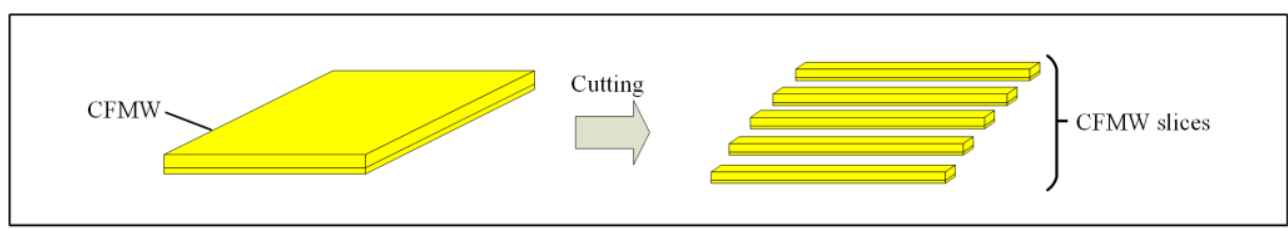

Cutting Process

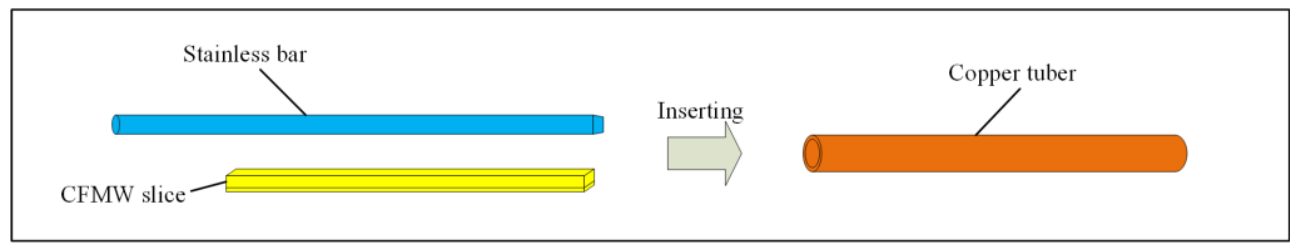

Filling Process

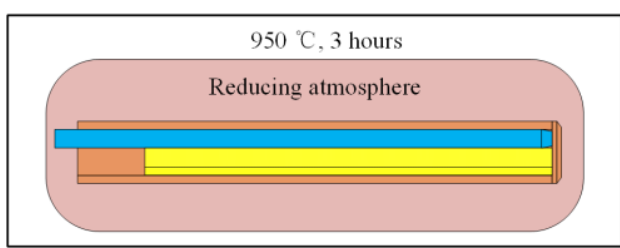

Sintering Process

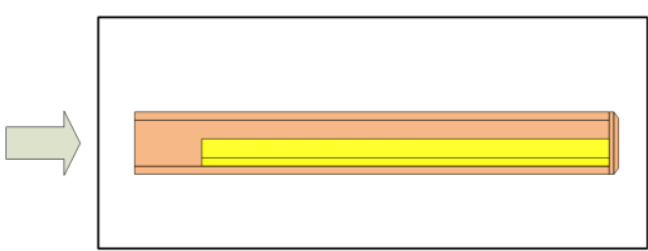

Rounding Process

Fig. 4. Sintering process of UTHP CFMW 


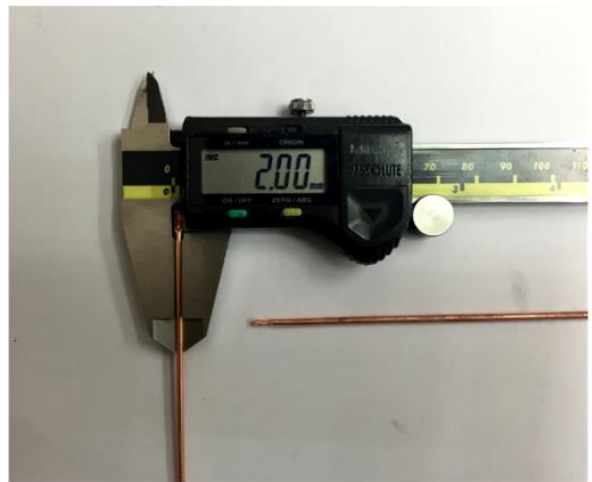

(a)

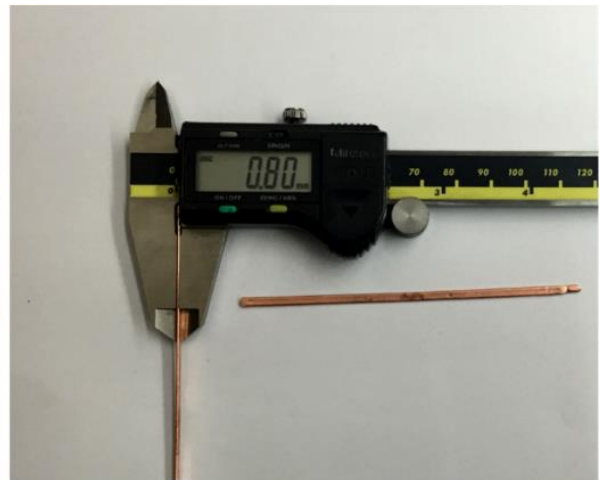

(b)

Fig. 5. Heat pipe samples: (a) cylindrical heat pipes and (b) UTHPs.

\section{Experimental setup}

\subsection{Experimental testing system}

Fig. 6 shows the schematic of UTHP experimental testing system. The system mainly includes the heating module, heat sink and temperature data acquisition module. The heating module is a copper heater with dimension of $30 \times 20 \times 20 \mathrm{~mm}^{3}$. The heater was heated by a heating rod supplied by a DC power source with an accuracy of $0.01 \mathrm{~W}$. The heating power was accurately obtained by adjusting the current and voltage value of DC power output. The heat sink with the same dimension of the heater was cooled by a water-cooling bath system. The material of the heat sink is copper. The cooling water was supplied by a constant temperature water tank and the output water temperature can be adjusted with an accuracy of $0.1{ }^{\circ} \mathrm{C}$. The flow rate of water could be controlled by the float flowmeter with an accuracy of $2 \mathrm{~L} / \mathrm{h}$. The temperature data were recorded by NI 9213 analog input data acquisition module with an accuracy of $0.1^{\circ} \mathrm{C}$. The temperature data were measured at five temperature measuring locations by T-type thermocouples with an accuracy of $0.5{ }^{\circ} \mathrm{C}$. The thermocouples were fixed on two PU blocks and tightly attached on the UTHPs surface.

The UTHP sample was placed horizontally on the experimental apparatus with one end on the 
heating block and the other end on the heat sink during the experiment. The contact thermal resistances of evaporator and condenser were reduced by using a layer of the thermal grease with the thermal conductivity of $6.0 \mathrm{~W} /(\mathrm{m} \cdot \mathrm{K})$ on the interface between the UTHP and the copper blocks. The evaporator section was compressed by a PU block with the temperature measuring locations of $T_{1}$ and $T_{2}$. The condenser section was compressed by the other PU block with the temperature measuring locations of $T_{4}$ and $T_{5}$. The evaporator length was equal to the condenser length [19]. The evaporator and condenser sections were separated by an adiabatic section with a length of $35 \mathrm{~mm}$. A block with the temperature measuring location $T_{3}$ was clamped on the adiabatic section. UTHPs were thermally insulated with thermal insulation material during the testing process. The cooling water ran through the condenser copper block at the flow rate of $20 \mathrm{~L} / \mathrm{h}$ and at the temperature of $50{ }^{\circ} \mathrm{C}$.

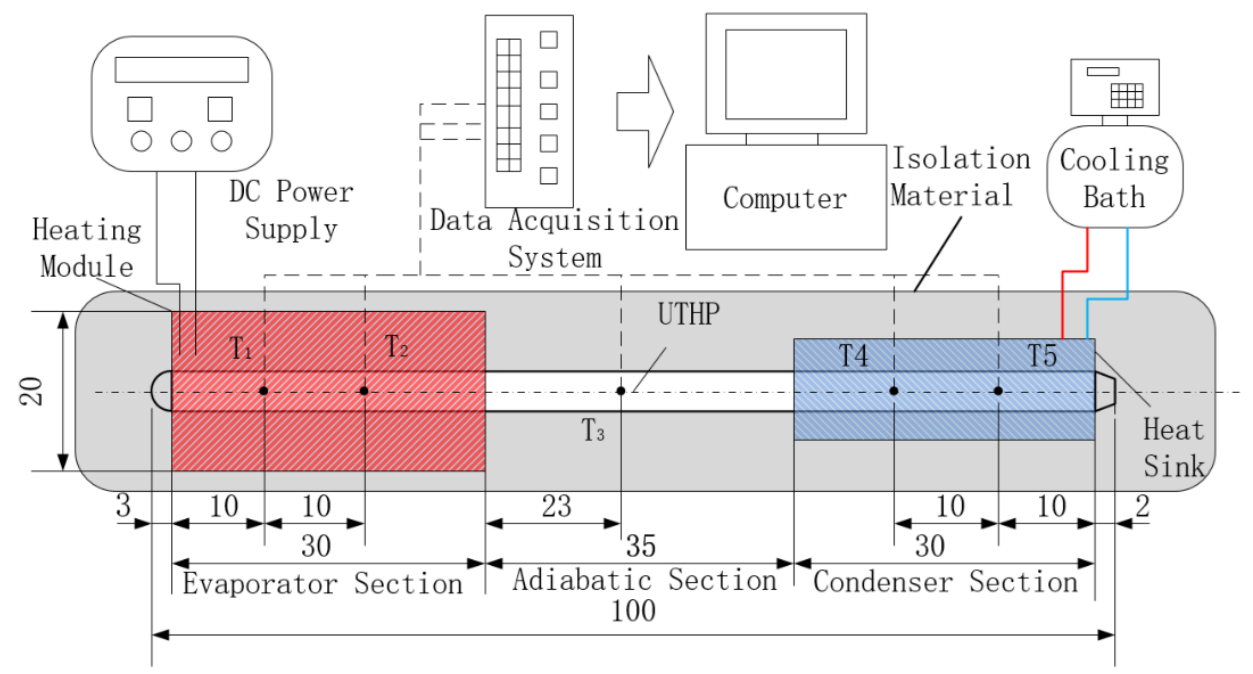

Fig. 6. Schematic of the experiment testing system

Heat power input to the evaporator copper block increased from $2.5 \mathrm{~W}$ to $5 \mathrm{~W}$ with an increment of $0.5 \mathrm{~W}$. The data of the five temperature measuring locations were recorded until the UTHPs reached the equilibrium state (the maximum temperature difference is less than $5{ }^{\circ} \mathrm{C}$ ), under which the temperature variances are less than $0.1^{\circ} \mathrm{C}$. With the increment of heat input, more and more working 
fluid in the evaporator changed to vapor and transferred heat to the condenser. If the input heat was too larger for the UTHP to take away, dry-out phenomenon will occur with significant temperature rise in the evaporator section. The heat load is defined as the maximum heat transport power of the UTHP.

The thermal performance of UTHP includes the axial temperature distribution, temperature difference, heat transport capacity, thermal resistance and so on. The average temperature of evaporator section $T_{e-a v e}$ and the average temperature of condenser section $T_{c-a v e}$ are defined respectively by:

$$
\begin{aligned}
& T_{e-a v e}=\frac{T_{1}+T_{2}}{2} \\
& T_{\mathrm{c}-\text { ave }}=\frac{T_{4}+T_{5}}{2}
\end{aligned}
$$

The average temperature difference $\Delta T$ is given as follows:

$$
\Delta T=T_{e-a v e}-T_{c-a v e}
$$

The temperature of adiabatic section $T_{a}$ is equal to $T_{3}$.The thermal resistance of evaporator section $R_{\text {eva }}$

is given by:

$$
R_{e v a}=\frac{T_{e-a v e}-T_{a}}{Q}
$$

where $Q$ is the heat load. The thermal resistance of condenser section $R_{c o n}$ is defined by:

$$
R_{c o n}=\frac{T_{a}-T_{c-a v e}}{Q}
$$

The porosity of the CFMW was calculated by soaking the wick into deionized water until it become saturated [5]. The porosity of wick is defined by:

$$
\varepsilon=\frac{V_{l}}{V_{w}} \times 100 \%
$$

where $V_{l}$ is the volume of saturated water and the $V_{w}$ is the volume of CFMW.

The volume of pores inside the CFMW can be given by:

$$
V_{p}=\varepsilon \cdot V_{w}
$$

where $\varepsilon$ is the porosity of CFMW. 
The filling ratio $\eta$ is defined by:

$$
\eta=\frac{V_{f}}{V_{p}} \times 100 \%
$$

where $V_{f}$ is the volume of filling fluid. The filling ratio is $100 \%$ when the CFMW is saturated, namely the $V_{f}$ is equal to $V_{p}$. The structure of the UTHP is shown in Fig. 7 and the parameters of UTHP are listed in Table 2.

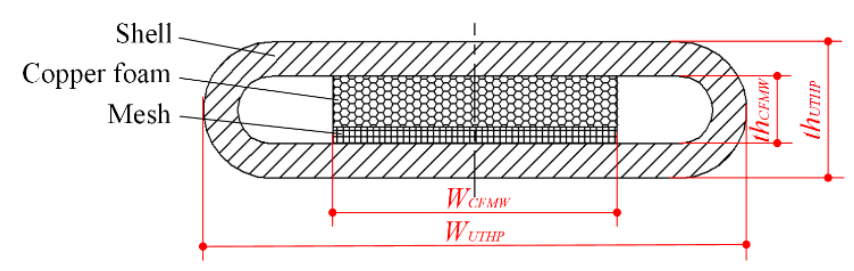

Fig. 7. Schematic of the UTHP

Table 2 Parameters of UTHP

\begin{tabular}{lc}
\hline Parameters & Dimension \\
\hline$L_{U T H P}(\mathrm{~mm})$ & 100 \\
$t_{\text {UTHP }}(\mathrm{mm})$ & 0.8 \\
$W_{U T H P}(\mathrm{~mm})$ & 0.27 \\
$t_{C F M W}(\mathrm{~mm})$ & 0.40 \\
$W_{C F M W}(\mathrm{~mm})$ & 0.13 \\
$p_{C F M W}$ & $67 \%$ \\
$V_{C F M W}\left(\mathrm{~mm}^{3}\right)$ & 52 \\
\hline
\end{tabular}

3.2 Uncertainty analysis

The experimental testing system includes the heating module, heat sink and temperature data acquisition module. The uncertainty of the testing system arises mainly from the heating module and temperature acquisition module. The maximum measurement error of the heating module and the temperature acquisition module are $0.01 \mathrm{~W}$ and $0.5{ }^{\circ} \mathrm{C}$, respectively. The relative measurement errors 
of thermal resistances are calculated with the following formula [20]:

$$
\frac{E(R)}{R}=\frac{\sqrt{\sum\left(\frac{\partial R}{\partial T_{i}} E_{T_{i}}\right)^{2}}}{R}
$$

where $E(R)$ is the measurement error of thermal resistances and $E_{T i}$ is the maximum measurement error, which is defined as $T_{i}$. Fig. 8 shows the relative measurement error of UTHPs. The relative measurement errors of evaporation and condensation thermal resistances are very close. As heat input power increases to $5 \mathrm{~W}$, the relative measurement errors of evaporation and condensation thermal resistances drop sharply and they are below $12.5 \%$.

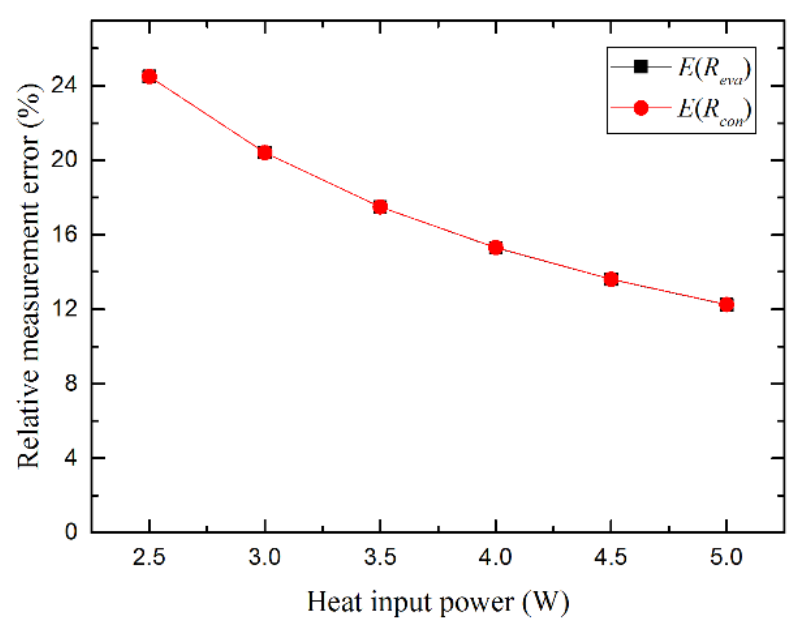

Fig. 8 Relative measurement error of UTHPs.

\section{Results and Discussion}

\subsection{SEM photographs of composite wick structure}

Fig. 9 shows the SEM photographs of CFMW structure. The copper foam and mesh are sintered together to produce the CFMW structure. The total thickness of UTHP is $0.8 \mathrm{~mm}$ and the width is about $2.7 \mathrm{~mm}$. After flattening, the upper and bottom surfaces of CFMW contact closely with the inner wall of the copper tube. The thickness of CFMW is $0.4 \mathrm{~mm}$ and the width is about $1.3 \mathrm{~mm}$. The independent channels of liquid and vapor of CFMW can be observed clearly in Fig. 9(a). The CFMW is sintered in the middle position of the inner tube in order to provide a liquid circulation passage for the 
working fluid. The vapor flows in the channels on both sides of the wick structure. The composite wick can reach higher heat flux than the single wick because the composite wick can make more menisci inside the wick than the single wick [21]. The copper foam wick has the advantages of high porosity and large capillary force. The mesh wick is easy to bend and it has high mechanical strength. Thus, CFMW combines with the advantages of both.

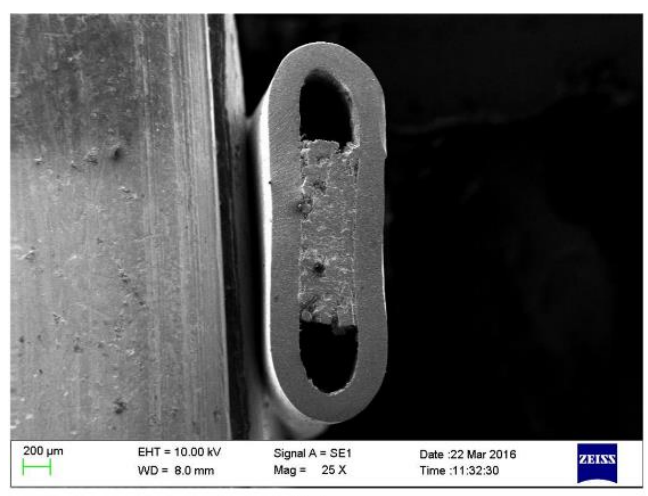

(a)

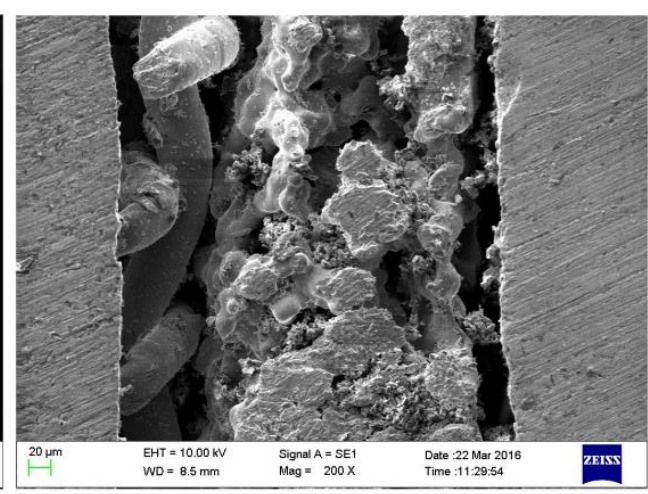

(b)

Fig. 9. SEM photographs of UTHP: (a) cross section and (b) partial magnification.

\subsection{Temperature distribution and heat transport capacity}

Thermal performance tests with filling ratios from $57 \%$ to $115 \%$ were conducted to find out the optimum filling ratio for UTHPs with CFMW. Fig. 10 shows the axial temperature distribution of UTHP samples under incremental heat input ranging from $2.5 \mathrm{~W}$ to $5 \mathrm{~W}$ until dry out occurred. Fig. 11 shows the heat transport power of UTHPs with different filling ratios. The temperature of UTHP samples increased firstly and then decreased with increasing the distance away from the evaporator end. $T_{2}$ temperature reading is higher than the $T_{1}$, the reason is that the internal cavity of UTHP sample is very narrow. At a lower heating power, the working fluid is easy to accumulate in the evaporator section of UTHP sample with a lower liquid filling ratio. The working fluid accumulates in the end of evaporator section, resulting in a lower temperature of it. $T_{5}$ has the lowest temperature with the longest distance away from the heating rod. The UTHP samples showed good temperature uniformity at low heat input. The maximum temperature difference was below $1.2{ }^{\circ} \mathrm{C}$ with the heat input of $2.5 \mathrm{~W}$. The UTHP samples with the filling ratio of $85 \%$ have the smallest temperature difference under the heat input ranging from $2.5 \mathrm{~W}$ to $4.5 \mathrm{~W}$. When the UTHP samples worked normally, the maximum heat transport power of the UTHP samples increased firstly and then decreased with the increase of the filling ratio. When the filling ratio is $100 \%$, the UTHP samples reach the maximum heat transport 
power of $5 \mathrm{~W}$, and the maximum temperature difference is $3.7{ }^{\circ} \mathrm{C}$. When the filling ratio is $57 \%$, the maximum heat transport power of UTHP samples is $3 \mathrm{~W}$ and the maximum temperature difference is $4.2{ }^{\circ} \mathrm{C}$. When the filling ratio is $115 \%$, the maximum heat transport power is $4 \mathrm{~W}$ and the maximum temperature difference is $4.7^{\circ} \mathrm{C}$. With the increase of the heating power, the UTHP samples with the filling ratio of $57 \%$ could not take away all the heat. Dry-out phenomenon occurred with a significant temperature rise in the evaporator section. Dry-out phenomenon broken the balance of liquid-vapor between evaporator and condenser section. The working fluid in the evaporator section undergoes superheating and forms nucleate boiling when the dries out occurred at sufficiently high heat input. The bubbles formed by nucleate boiling be trapped in the CFMW, thereby breaking the circulation of the working fluid. With the increase of the heating power, liquid clogging phenomenon occurred in the UTHP samples with the filling ratio of $115 \%$, which resulted in rapid temperature rise in the condenser section. The increase of the temperature difference of the UTHP is caused by the liquid accumulated exceeds the reflow capacity of the CFMW in the condensation section. The exceeded working fluid in the condensation section is blocked and cooled continuously by the cooling water, resulting in a significant temperature decrease in the condensation section and an increase in the overall temperature difference of the heat pipe. Therefore, the optimum filling ratio of UTHP samples is $100 \%$ and the maximum heat transport capacity is $5 \mathrm{~W}$. 


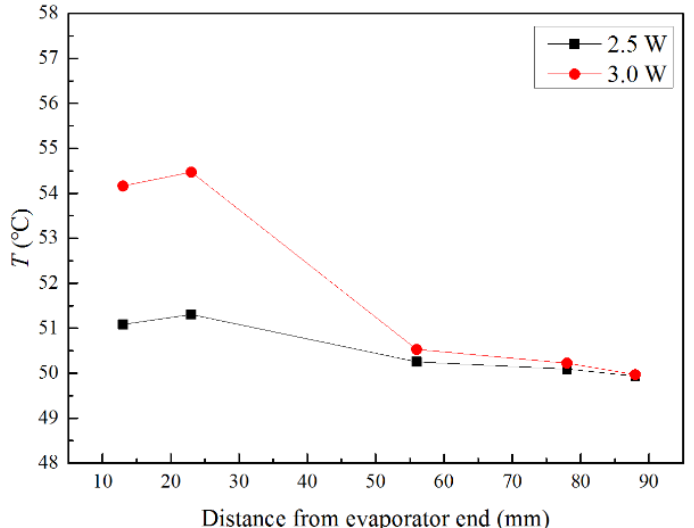

(a)

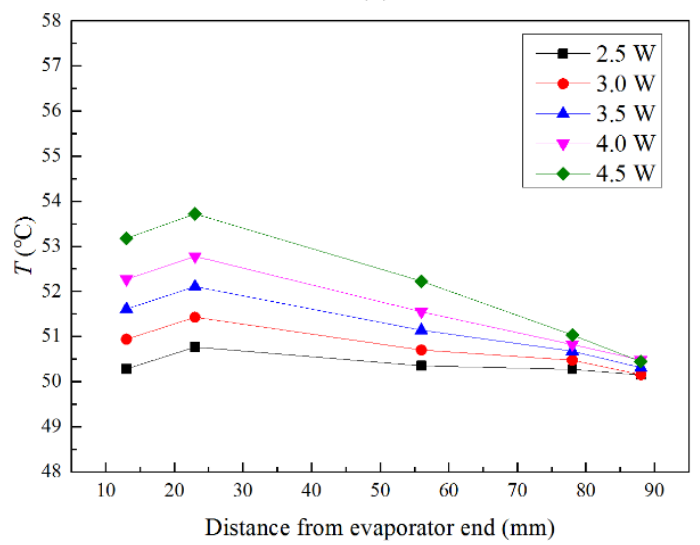

(c)

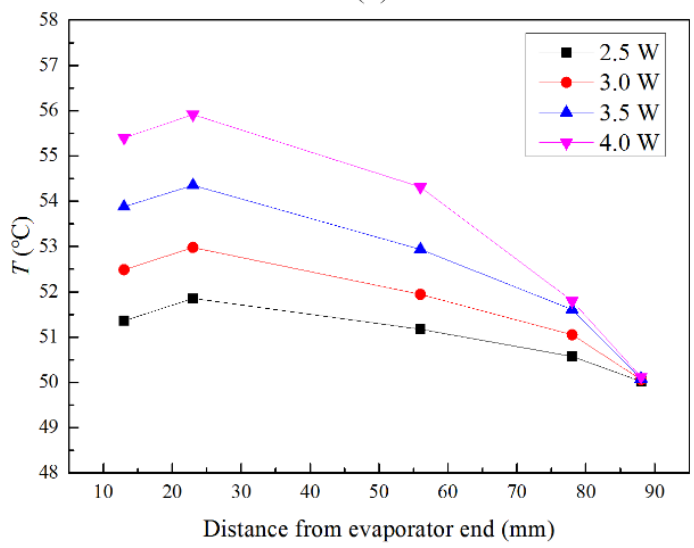

(e)

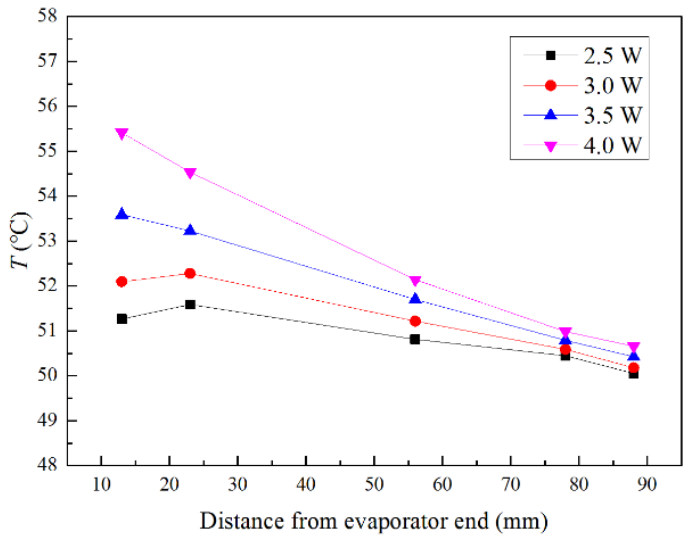

(b)

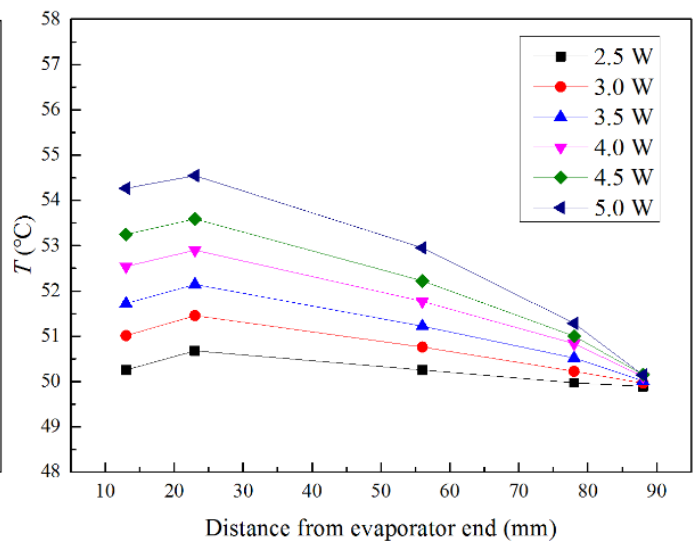

(d)

Fig. 10. Temperature distribution of UTHPs under different filling ratios: (a) $57 \%$, (b) $71 \%$, (c) $85 \%$, (d) $100 \%$ and (e) $115 \%$. 


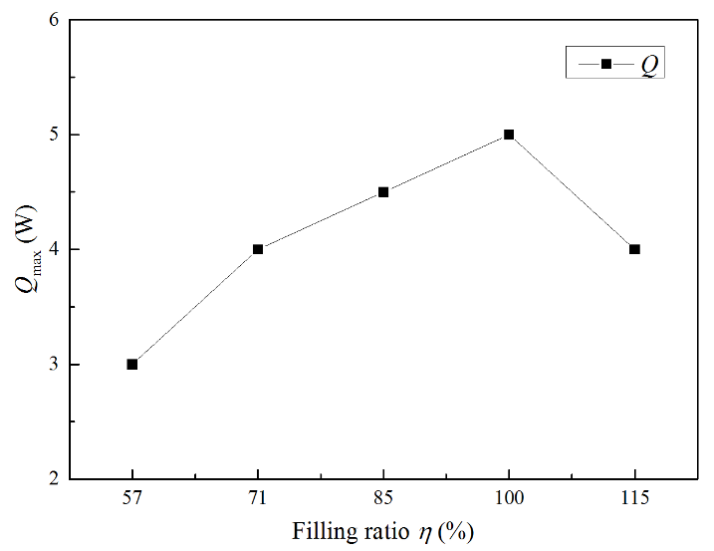

Fig. 11. Heat transport capacities of UTHPs under different filling ratios.

\subsection{Thermal resistance}

Fig. 12 shows the evaporation and condensation thermal resistances of UTHPs with different filling ratios under different heat loads. In general, the thermal resistances of the UTHP samples increased gradually with the increasing heat power. The thermal resistances of UTHP samples increased rapidly with the increasing heat input when the filling ratios are $57 \%$ and $71 \%$. It is because that the working fluids in the evaporator were not enough, the dry-out phenomenon occurred with rapid evaporator temperature rise. The evaporation thermal resistance of UTHP samples with the filling ratio of $115 \%$ first increased and then decreased slightly. According to the thin-film heat transfer mechanism, the thin film existing on the evaporative interface will enlarge the evaporation thermal resistance of UTHPs under high filling ratios. The evaporation thermal resistances of UTHP samples with the filling ratio of $85 \%$ and $100 \%$ increased slowly with the increasing heat input. With the increase of heating power, the condensation thermal resistance of UTHP samples with the filling ratio of $115 \%$ increased rapidly, and the increase rate became faster when the heating power was over $3.5 \mathrm{~W}$. According to the theory of the thin-film heat transfer theory, working fluid gathered at the condensation section in the UTHPs with high filling ratio, and the thin film at the vapor-liquid interface lead to large condensation thermal resistance. It can be seen that too low or too high filling ratios will degrade the heat transfer performance of UTHPs and increase the thermal resistances. The optimum filling ratio of experimental UTHPs is $100 \%$ and the maximum heat transport capacity is $5 \mathrm{~W}$, with the evaporation thermal resistance of $0.29 \mathrm{~K} / \mathrm{W}$ and the condensation thermal resistance of $0.45 \mathrm{~K} / \mathrm{W}$. 


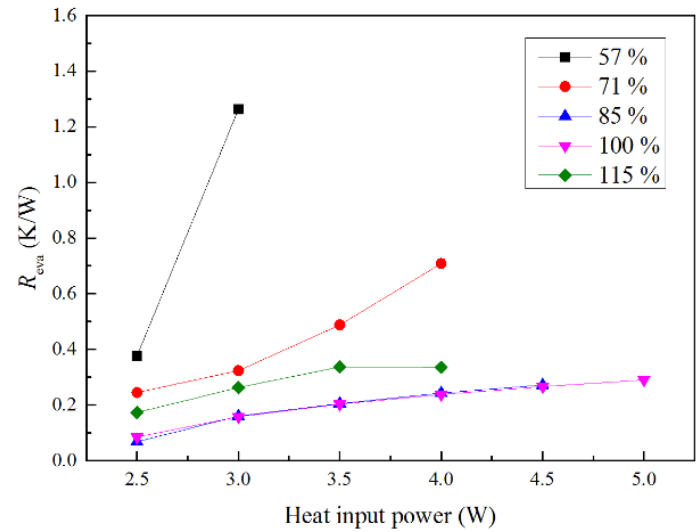

(a)

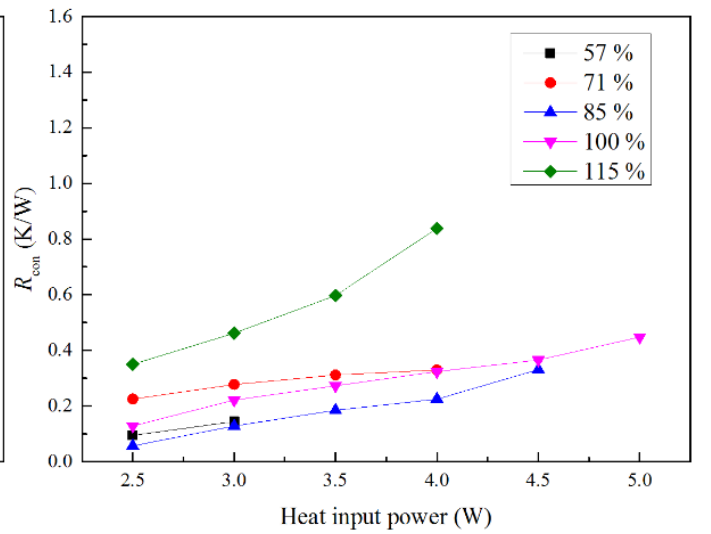

(b)

Fig. 12. Thermal resistances of UTHPs under different filling ratios: (a) evaporation thermal resistance and (b) condensation thermal resistance.

\section{Conclusion}

UTHPs with the length of $100 \mathrm{~mm}$ and the thickness of $0.8 \mathrm{~mm}$ are fabricated and investigated in the study. Thermal performance and optimal filling ratios of UTHPs are measured. Conclusions can be summarized as follows:

(1) UHTPs with composite wick were produced by flattening cylindrical heat pipes with outer diameter of $2 \mathrm{~mm}$. The width of UTHPs is about $2.7 \mathrm{~mm}$. The composite wick structure is made of CFMW that combines the good heat transfer performance of copper foam and the high mechanical strength of mesh.

(2) The filling ratio mainly affects the response time and the temperature uniformity of UTHPs. The optimum filling ratio of UTHPs is $100 \%$ and the maximum temperature difference is $3.7^{\circ} \mathrm{C}$ under the maximum heat transport capacity of $5 \mathrm{~W}$.

(3) The thermal resistances of UTHPs increase gradually with the increasing heat power before drying out. Too low or too high filling ratios will reduce the heat transfer efficiency of UTHPs by increasing the thermal resistances. With the optimum filling ratio of $100 \%$, evaporation thermal 
resistance of UTHP is $0.29 \mathrm{~K} / \mathrm{W}$ and the condensation thermal resistance is $0.45 \mathrm{~K} / \mathrm{W}$ at the heat load of $5 \mathrm{~W}$

\section{Acknowledgements}

This project is supported by National Natural Science Foundation of China (Grant No. 51675185), Guangdong Provincial Natural Science Foundation of China (Grant No. S2013020012757), and EU project PIIF-GA-2012-332304 (Grant No. ESR332304).

\section{References}

[1] G. Zhou, J Li, L Lv. An ultra-thin miniature loop heat pipe cooler for mobile electronics[J]. Appl. Therm. Eng. 109 (2016): 514-523.

[2] X. Yang, Y.Y. Yan, D. Mullen, Recent developments of lightweight, high performance heat pipes, Appl. Therm. Eng. 33-34(2012) 1-14.

[3] N. Putra, Yanuar, F.N. Iskandar. Application of nanofluids to a heat pipe liquid-block and the thermoelectric cooling of electronic equipment, Exp. Therm. Fluid Sci. 35(2011): 1274-1281.

[4] R. Kempers, A.J. Robinson, D. Ewing, et al., Characterization of evaporator and condenser thermal resistances of a screen mesh wicked heat pipe. Int. J. Heat Mass Transf. 51(2008): 6039-6046.

[5] Y. Li, W.J. Zhou, J.B. He, et al., Thermal performance of ultra-thin flattened heat pipes with composite wick structure, Appl. Therm. Eng. 102(2016) 487-499.

[6] G. Zhou, J. Li, L. Lv, An ultra-thin miniature loop heat pipe cooler for mobile electronics, Appl. Therm. Eng. 109(2016) 514-523.

[7] M. Famouri, G. Carbajal, C. Li, Transient analysis of heat transfer and fluid flow in a polymer-based 
micro flat heat pipe with hybrid wicks, Int. J. Heat Mass Transf. 70 (2014) 545-555.

[8] H.J. Kim, S.H. Lee, Y.C. Kong, et al., Long-term reliability of the thermal performance of a flat-plate heat pipe using a prognostics method, Int. J. Heat Mass Transf. 82 (2015) 369-372.

[9] K.H. Do, S.J. Kim, S.V. Garimella, A mathematical model for analyzing the thermal characteristics of a flat micro heat pipe with a grooved wick, Int. J. Heat Mass Transf. 51(2008) 4637-4650.

[10] J.H. Liou, C.W. Chang, C. Chao, et al., Visualization and thermal resistance measurement for the sintered mesh-wick evaporator in operating flat-plate heat pipes, Int. J. Heat Mass Transf. 53(2010) 1498-1506.

[11] S.C. Wong, J.H. Liou, C.W. Chang, Evaporation resistance measurement with visualization for sintered copper-powder evaporator in operating flat-plate heat pipes, Int. J. Heat Mass Transf., 53(2010), 3792-3798.

[12] S. Lips, F. Lefèvre, J. Bonjour, Combined effects of the filling ratio and the vapor space thickness on the performance of a flat plate heat pipe, Int. J. Heat Mass Transf. 53(2010) 694-702.

[13] J.S. Chen, J.H. Chou, Cooling performance of flat plate heat pipes with different liquid filling ratios, Int. J. Heat Mass Transf. 77(2014) 874-882.

[14] H.Z. Tao, H. Zhang, J. Zhuang, et al., Experimental study of heat transfer performance in a flattened AGHP, Appl. Therm. Eng. 28(2008) 1699-1710.

[15] Y. Li, J.B. He, H.F. He, et al., Investigation of ultra-thin flattened heat pipes with sintered wick structure, Appl. Therm. Eng. 86(2015)106-118.

[16] K.T. Lin, S.C. Wong, Performance degradation of flattened heat pipes, Appl. Therm. Eng. 50 (2013) 46-54.

[17] Y. Li, H.F. He, Z.X. Zeng, Evaporation and condensation heat transfer in a heat pipe with a 
sintered-grooved composite wick, Appl. Therm. Eng. 50(2013) 342-351.

[18] J.C. Hsieh, H.J. Huang, S.C. Shen. Experimental study of micro rectangular groove structure covered with multi mesh layers on performance of flat plate heat pipe for LED lighting module. Microelectron. Reliab. 52 (2012): 1071-1079.

[19] S. Wang, J. Chen, Y. Hu, et al., Effect of evaporation section and condensation section length on thermal performance of flat plate heat pipe, Appl. Therm. Eng. 31(2011) 2367-2373.

[20] S.J. Kline, F.A. McClintock, Describing uncertainties in single-sample experiments, Mech. Eng. 75 (1953) 3-9.

[21] Y. Li, S.L. Chen, B.L. He, et al., Effects of vacuuming process parameters on the thermal performance of composite heat pipes, Appl. Therm. Eng. 99(2016) 32-41. 